\title{
Diseño de una Planta para la Producción de Aceite de Palta (Persea Americana Mill)
}

\author{
Design of a Plant for the Production of Avocado oil (Persea Americana Mill)
}

\author{
José Antonio Legua Cárdenas ${ }^{1}$, Pedro Luis Romero y Otiniano², \\ Christian Giancalo Alvarado Auccapuri ${ }^{2}$, Yasmin Jesús Vélez Chang ${ }^{1}$, Felicia Antonia Guerrero Hurtado ${ }^{1}$
}

\section{RESUMEN}

Objetivo: El objetivo del presente trabajo es proponer una tecnología para incrementar el valor agregado de la palta sobre todo con los residuales de palta que resulta luego de una selección generalmente para exportación. Materiales y Métodos: Para el desarrollo del siguiente trabajo de investigación se emplearon los siguientes materiales y Equipos: Prensa Hidráuica Apex, centrifuga marca Janetzki, secador de bandeja de tiro forzado, balanza digital, mortero, vasos Erlenmeyer.

El método de Investigación utilizado es el científico. En esta propuesta de tecnología se trata de utilizar la experiencia y tecnología aplicada al proceso de extracción de aceite de oliva a la extracción de aceite de las paltas. Para su extracción se aplican exclusivamente operaciones mecánicas en frío (molienda, centrifugación y decantación), lo cual permite obtener un producto $100 \%$ natural, libre de todo agente químico. El procedimiento desarrollado a nivel laboratorio es el siguiente: Deshidratación, Trituración, Prensado. Centrifugación.

Palabras clave: Diseño de planta, aceite de palta.

\section{ABSTRACT}

Objective: The objective of this paper is to propose a technology to increase the added value of the avocado especially with avocado residuals then a selection is generally for export. Materials and Methods: Apex Press Hidráuica, centrifuge Janetzki brand, tray dryer forced draft, digital scale, mortar, Erlenmeyer vessels: For the development of this research work the following materials and equipment were used.

The research method used is the scientist. In this proposed technology it is to use the expertise and technology applied to oil extraction process of olive oil extraction of avocados. For removal only cold mechanical operations (milling, centrifugation and decanting) apply, which allows for a $100 \%$ natural, free of any chemical agent. The procedure developed at laboratory level is as follows: Dehydration, Shredding, Pressing. Centrifugation.

Keywords: plant design, avocado oil.

\footnotetext{
Facultad de Ingeniería Química y Metalúrgica. Universidad Nacional José Faustino Sánchez Carrión. Lima - Perú.

${ }^{2}$ Facultad de Ingeniería Química y Metalúrgica. Universidad Nacional Mayor de San Marcos. Lima - Perú.
} 
El objetivo del presente trabajo es proponer una tecnología para incrementar el valor agregado de la palta sobre todo con los residuales de palta que resulta luego de una selección generalmente para exportación. En este caso se aplica normas técnicas peruanas e internacionales que establecen los requisitos mínimos de calidad que deben cumplir las paltas, las principales son las siguientes : El contenido de aceite debe ser mínimo $9.5 \%$ y máximo $14 \%$; debe tener un color uniforme, característico a la variedad; la apariencia física debe ser limpia de impurezas, un calibre máximo a $10 \%$ de frutas fuera de rango, con un rango máximo permisible de desviación de +/-8gr.

La investigación bibliográfica se realizó en paltas de la variedad Hass; para caracterizar la situación actual en cuanto a la información técnica para la prolongación de la vida útil de la palta en diferentes alternativas tecnológicas de conservación, tal como la de atmósfera controlada, modificada, irradiación ultravioleta y refrigeración común de tal manera que el uso de estas tecnologías ayudan a preservar la calidad y condición por más tiempo; debido a la efectividad de estas tecnologías. Se concluye que el método de conservación más recomendable es la atmósfera controlada retrasando el ablandamiento, disminuye la sensibilidad al daño por frío y evita la incidencia de pudrición.

Los aguacates tienen una vida de almacenamiento relativamente corto, limitado principalmente por la expresión de daño por frío interno, pero se pudre son una limitación para la fruta cultivada en muchos países la temperatura óptima de almacenamiento es por lo general alrededor de $6^{\circ} \mathrm{C}$ y temperaturas por debajo de 3 a $4^{\circ} \mathrm{C}$.

El presente trabajo propone industrializar el fruto de la palta para obtener aceite, una torta de filtración que se le puede dar uso para la preparación de alimentos balanceados para animales, así también la pepa o semilla de la palta también se le puede utilizar para incrementar la rentabilidad global del proceso productivo, contribuyendo así a la sostenibilidad de la actividad industrial y al mismo tiempo reduciendo sensiblemente el impacto medioambiental.

La semilla es un derivado descartado en la obtención industrial del aceite de pulpa y sería una fuente de ácidos grasos insaturados y otros fitoconstituyentes.

\section{MATERIALES Y MÉTODOS}

\section{Descripción del Área de Estudio}

El estudio se ha aplicado al fruto de la palta al fin de obtener aceite de palta para resolver parte del problema con las paltas residuales luego de una selección de paltas para exportación.

\section{Población y Muestra.}

La población o universo de la Investigación está constituido el fruto de la palta en este caso de Santa Eulalia-Lima.

La muestra de la población en una cantidad de $20 \mathrm{Kg}$ de paltas rechazadas de una selección para exportación.

\section{Equipos y Materiales}

Para el desarrollo del siguiente trabajo de investigación se emplearon los siguientes materiales y Equipos:

Prensa Hidráuica Apex.

Centrifuga marca Janetzki

Secador de bandeja de tiro forzado.

Balanza digital, mortero, vasos erlenmeyer,

Soporte Informático: disco duro, USB, CD.

Cámara fotográfica, libreta de apuntes.

\section{Método}

Este es un caso de Investigación aplicada y un nivel de investigación experimental.

El método de Investigación utilizado es el científico.

En esta propuesta de tecnología se trata de utilizar la experiencia y tecnología aplicada al proceso de extracción de aceite de oliva a la extracción de aceite de las paltas. Para su extracción se aplican exclusivamente operaciones mecánicas en frío (molienda, centrifugación y decantación), lo cual permite obtener un producto $100 \%$ natural, libre de todo agente químico.

El procedimiento básico desarrollado a nivel laboratorio es el siguiente:

a. Deshidratación: Se sometió la pulpa a un secado por aire caliente a $60^{\circ} \mathrm{C}$, la velocidad del aire fue de $5 \mathrm{~m} / \mathrm{seg}$ y la altura de la cama de $0.5 \mathrm{~cm}$.

b. Trituración: Se realizó esta operación con la finalidad de reducir el tamaño de las partículas de la muestra deshidratada y facilitar la salida del aceite durante el prensado. Para esta operación se utilizó un mortero.

c. Prensado: En esta operación se empleó la prensa hidráulica, para muestras de diferentes contenidos de humedad (30\%, 25\%, 15\%, 10\%, 7.5\% y $5 \%$ ) se uso la cantidad constante de $200 \mathrm{~g}$. El prensado se efectuó a temperatura ambiente $\left(20^{\circ} \mathrm{C}\right)$ y a una presión máxima de $150 \mathrm{~kg} / \mathrm{cm} 2$. En todos los casos fue necesario el empleo de bolsas de lona como medio filtrante. 


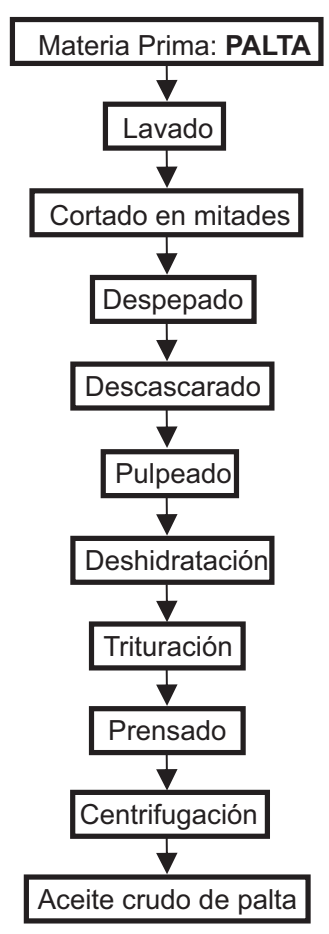

Figura 1. Aceite extraído mecánicamente.

d. Centrifugación: Después del prensado se realizó una centrifugación, con el objeto de separar el agua y las impurezas contenidas en el aceite, después de la cual el aceite extraído se recogió en vasos previamente tarados, se empleó en esta operación la centrifuga a 6000RPM durante 10 minutos.

e. Extracción por solventes a partir de la torta resultante del prensado: Mediante el método Soxhlet con hexano como solvente. Esta operación se realizó con el objeto de recuperar el aceite que no pudo ser extraído mediante el prensado.

De esta forma se obtiene el aceite de palta el cual tiene un gran contenido de "grasas buenas" (más de un $75 \%$ ), entendiéndose éstas por aquellas monoinsaturadas. Además es rico en vitamina E, vitamina $B$ y no contiene colesterol ni carbohidratos. Éste ayuda a disminuir el colesterol negativo y aumentar el colesterol bueno. Es rico en beta-sitosteroles, los que han demostrado clínicamente disminuir los niveles sanguíneos de colesterol malo.

Su contenido en acido grasos esenciales, minerales, proteínas, vitaminas es muy útil para la industria cosmetológica, ya que favorece notablemente a pieles deshidratadas, o prematuramente maltratadas, es muy eficiente para el tratamiento de soriasis, eczemas y caída del cabello.
Tabla 1. (Costos de Equipos para el proceso de la palta)

\begin{tabular}{lc}
\hline \multicolumn{1}{c}{ Equipo } & Costo (\$) \\
\hline Faja transportadora con motor & 8500 \\
$\begin{array}{l}\text { Mesa de descascarado (2 mesas) + faja } \\
\text { transportadora con motor }\end{array}$ & 7000 \\
Secador rotario continuo & 18000 \\
Molino & 4500 \\
Prensa hidráulica & 28000 \\
Tanque de llenado & 2500 \\
Bomba & 400 \\
Filtro bolsa & 2500 \\
Elevador de cangilones & 2800 \\
Tolva & 2500 \\
Equipo de envasado & 8000 \\
Total & 84700 \\
\hline
\end{tabular}

Además de estos notables beneficios para el ser humano se le agregan grandes condiciones para el arte culinario ya que es muy conveniente en frituras por su alto punto de quemado o humo, esto permite usarlo en forma repetida sin causar daño en comparación a los tipos de aceite disponibles en el mercado.

El procedimiento llevado a escala industrial comprendería los siguientes costos, que se muestran en la Tabla 1.

RESULTADOS

Los resultados se presentan en las Tabla 1 y Figura 1 donde se presentan los resultados de costos y diagrama de flujo respectivamente,

\section{DISCUSIÓN}

Los resultados muestran la posibilidad de industrializar la palta en sus residuales de paltas no seleccionadas para exportación y así evitar la pérdida económica que tiene los agricultores para mejorar sus ingresos y tener expectativa económica para hacer otros proyectos alternativos para dar mayor valor agregado a esta actividad económica.

El aceite que se obtiene al finalizar el procesamiento a la palta tiene un ácido grado predominante que es el ácido oleico, el cual se ha detectado que disminuye a medida que la fruta sobrepasa su nivel óptimo de madurez de cosecha, los otros ácidos grasos que se encuentran son el ácido palmitoleico, linolenico y esteárico. 


\section{CONCLUSIONES}

El diseño de etapas de proceso que se desarrolló a nivel laboratorio presento un resultado óptimo que se podría escalar a nivel industrial con eficiencia.

El procesamiento de la fruta palta incluye las siguientes etapas: Deshidratación, Trituración, Prensado, Centrifugación y Extracción por solventes.

El proyecto es sustentable económicamente para el valor de un VAN $=0$ para un TIR igual a 45 días.

El contenido graso es una característica de la variedad de palta que es representativa de la madurez de la fruta, ya que la tendencia es que aumente a medida que madure la palta.

\section{REFERENCIAS BIBLIOGRAFICAS}

Barbosa-Martína B et al (2016) Food and Bioproducts Processing. Chemical and technological properties of avocado (Persea americana Mill.)

Industrial and Engineering Chemistry Research Volume 53, Issue 32, 13 Pages 12705-12719.

Kiger F. at el (1980) Preservacion de palta (Persea Americana, Mill) variedad fuerte, mediante el uso de aditivos químicos y bajas temperaturas. Investigación Agrícola. Chile. Vol. $6 \mathrm{~N}^{\circ}$ 1:33-38.

Olaetea J. at el (1999) Determinación de la evolución y caracterización de los aceites en paltas (Persea Americana, Mill) cvs. Fuerte y Hass cultivados en Chile. Revista Chapingo Serie Horticultura 5: 117-122.

Yabart M. (2012) Post cosecha de palta Hass (Persea Americana, Mill) Monografia para optar el titulo profesional de Ingeniero en industrias alimentarias. Universidad Nacional José Faustino Sánchez Carrión.

Yahia E. \& Woolf A.(2011) Food Science, Technology and Nutrition. Pages 125-185, 186. 